\title{
PROP1 gene analysis in Portuguese patients with combined pituitary hormone deficiency
}

\author{
Manuel C. Lemos*†, Leonor Gomest, Margarida Bastost, Valeriano Leiteł§, Edward Limbert‡, \\ Davide Carvalhoף, Conceição Bacelar**, Mariana Monteiro**, Fernando Fonseca†t, Ana Agapito†t, \\ João J. Castroł‡, Fernando J. Regateiro* and Manuela Carvalheiro† \\ * Serviço de Genética Médica, Faculdade de Medicina da Universidade de Coimbra, Coimbra, †Serviço de Endocrinologia, \\ Diabetes e Metabolismo, Hospitais da Universidade de Coimbra, Coimbra, ¥Serviço de Endocrinologia, Instituto Português de \\ Oncologia Francisco Gentil, Lisboa, \$Faculdade de Ciências Médicas da Universidade Nova de Lisboa, Lisboa, 9Serviço de \\ Endocrinologia, Diabetes e Metabolismo, Hospital de São João e Faculdade de Medicina do Porto, Porto, ${ }^{* * S e r v i c ̧ o ~ d e ~}$ \\ Endocrinologia, Hospital Geral de Santo António, Porto, ††Serviço de Endocrinologia, Hospital de Curry Cabral, Lisboa, and \\ ¥Serviço de Endocrinologia, Hospital Militar Principal, Lisboa, Portugal
}

\section{Summary}

Objective Mutations of the PROP1 gene lead to combined pituitary hormone deficiency (CPHD), which is characterized by a deficiency of GH, TSH, LH/FSH, PRL and, less frequently, ACTH. This study was undertaken to investigate the molecular defect in a cohort of patients with CPHD.

Design, patients and measurements A multicentric study involving 46 cases of CPHD (17 familial cases belonging to seven kindreds and 29 sporadic cases) selected on the basis of clinical and hormonal evidence of GH deficiency, central hypothyroidism and hypogonadotrophic hypogonadism, in the absence of an identified cause of hypopituitarism. Mutations of PROP1 were investigated by DNA sequencing. Clinical, hormonal and neuroradiological data were collected at each centre.

Results PROP1 mutations were identified in all familial cases: five kindreds presented a $c$. 301-302delAG mutation, one kindred presented a $c .358 \mathrm{C} \rightarrow \mathrm{T}$ (R120C) mutation and one presented a previously unreported initiation codon mutation, $c$. $2 \mathrm{~T} \rightarrow \mathrm{C}$. Of the 29 sporadic cases, only two (6.9\%) presented PROP1 germline mutations (c. 301-302delAG, in both). Phenotypic variability was observed among patients with the same mutations, particularly the presence and age of onset of hypocortisolism, the levels of PRL and the results of pituitary imaging. One patient presented a sellar mass that persisted into adulthood.

Conclusions This is the first report of a mutation in the initiation codon of the PROP1 gene and this further expands the spectrum of known mutations responsible for CPHD. The low mutation frequency observed in sporadic cases may be due to the involvement of other unidentified acquired or genetic causes.

Correspondence: Dr Manuel C. Lemos, Serviço de Genética Médica, Faculdade de Medicina da Universidade de Coimbra, 3004-504 Coimbra, Portugal. Tel.: + 351 239825861; Fax: + 351 239823236; E-mail: mlemos@ci.uc.pt
(Received 18 January 2006; returned for revision 23 May 2006; finally revised 24 May 2006; accepted 31 May 2006)

\section{Introduction}

The PROP1 gene (Prophet of PIT1, OMIM 601538) is located on chromosome $5 \mathrm{q} 35.3^{1}$ and encodes a 226-amino acid transcription factor, which is involved in the early development of several anterior pituitary cell lineages. ${ }^{2}$

Mutations in this gene were originally discovered in a mouse model of dwarfism, the Ames mouse, ${ }^{3}$ which is characterized by a hypoplastic pituitary gland and combined deficiency of GH, TSH and PRL. In humans, PROP1 mutations cause combined pituitary hormone deficiency (CPHD), ${ }^{4}$ which has an autosomal recessive mode of inheritance and is associated with deficiency of LH, FSH, $\mathrm{GH}, \mathrm{TSH}, \mathrm{PRL}$ and, less frequently, ACTH.

Although patients often present with growth retardation, central hypothyroidism and hypogonadotrophic hypogonadism, the hormonal phenotype may vary in severity and in age of onset. ${ }^{5}$ This is illustrated by the observation of some patients who undergo spontaneous puberty before developing central hypogonadism and by the development of adrenal insufficiency in only a subset of patients. ${ }^{5}$ The mechanism underlying the variable expression of the CPHD phenotype is unknown.

Pituitary size can also vary among patients and, unlike the mouse model, it is not uncommon to find pituitary masses in affected children that can be potentially mistaken for craniopharyngiomas, Rathke's pouch cysts or pituitary adenomas, but that usually undergo involution. ${ }^{6,7}$

Several germline mutations of the $P R O P 1$ gene have been identified (Fig. 1, Table 1) affecting mainly the DNA-binding and transcriptional activation domain of the protein.

We have undertaken studies to uncover the molecular defect in a large cohort of patients with familial and sporadic CPHD. 


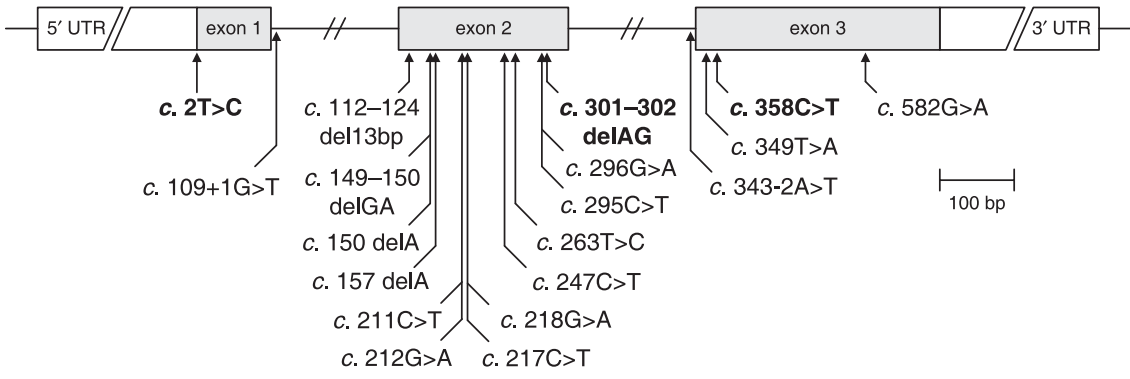

\begin{tabular}{|c|c|c|c|c|}
\hline Exon & Nucleotide change ${ }^{\star}$ & Mutation type & Predicted effect on protein & Ref. $\dagger$ \\
\hline 1 & c. $2 \mathrm{~T} \rightarrow \mathrm{C}$ & Initiation codon & No translation & This study \\
\hline $1 \ddagger$ & c. $109+1 \mathrm{G} \rightarrow \mathrm{T}$ & Splice-donor site & Abnormal mRNA splicing & 20 \\
\hline 2 & c. $112-124$ del $13 \mathrm{bp}$ & Deletion/frameshift & Truncation at codon 480 & 21 \\
\hline 2 & c. 149-150delGA & Deletion/frameshift & Truncation at codon 109 & 22 \\
\hline 2 & c. $150 \mathrm{delA}$ & Deletion/frameshift & Truncation at codon 164 & 23 \\
\hline 2 & c. $157 \mathrm{delA}$ & Deletion/frameshift & Truncation at codon 164 & 24 \\
\hline 2 & c. $211 \mathrm{C} \rightarrow \mathrm{T}$ & Missense & Amino acid change R71C & 25 \\
\hline 2 & c. $212 \mathrm{G} \rightarrow \mathrm{A}$ & Missense & Amino acid change $\mathrm{R} 71 \mathrm{H}$ & 25 \\
\hline 2 & c. $217 \mathrm{C} \rightarrow \mathrm{T}$ & Missense & Amino acid change R73C & 1 \\
\hline 2 & c. $218 \mathrm{G} \rightarrow \mathrm{A}$ & Missense & Amino acid change $\mathrm{R} 73 \mathrm{H}$ & 26 \\
\hline 2 & c. $247 \mathrm{C} \rightarrow \mathrm{T}$ & Nonsense & Truncation at codon 83 & 27 \\
\hline 2 & c. $263 \mathrm{~T} \rightarrow \mathrm{C}$ & Missense & Amino acid change F88S & 28 \\
\hline 2 & c. $295 \mathrm{C} \rightarrow \mathrm{T}$ & Nonsense & Truncation at codon 99 & 26 \\
\hline 2 & c. $296 \mathrm{G} \rightarrow \mathrm{A}$ & Missense & Amino acid change R99Q & 29 \\
\hline 2 & c. 301-302delAG & Deletion/frameshift & Truncation at codon 109 & 4 \\
\hline $3 \ddagger$ & c. $343-2 \mathrm{~A} \rightarrow \mathrm{T}$ & Splice-acceptor site & Intron retention/truncation $\$$ & 1 \\
\hline 3 & c. $349 \mathrm{~T} \rightarrow \mathrm{A}$ & Missense & Amino acid change F117I & 4 \\
\hline 3 & c. $358 \mathrm{C} \rightarrow \mathrm{T}$ & Missense & Amino acid change R120C & 4 \\
\hline 3 & c. $582 \mathrm{G} \rightarrow \mathrm{A}$ & Nonsense & Truncation at codon 194 & 30 \\
\hline
\end{tabular}

${ }^{*}$ Nucleotide +1 corresponds to the A of the ATG translation start codon.

$\dagger$ Only the first literature report is indicated for each mutation.

$\$$ Nearest exon (intronic mutation).

$\$ A$ smaller percentage of transcripts use an alternative cryptic splice site resulting in a four-codon deletion.
Fig. 1 Structure of the PROP1 gene and positions of mutations reported so far. The coding region is represented by shaded boxes. Introns and untranslated regions (UTRs) are not drawn to scale. Mutations found in the current study are highlighted.

Table 1. PROP1 germline mutations so far reported in the literature

\section{Subjects and methods}

\section{Subjects}

A multicentric study was launched in Portugal to screen for mutations of the PROP1 gene in patients with CPHD. Endocrinologists based at national endocrine referral centres, serving the northern, central and southern regions of the country, were invited to select patients from their outpatient clinics, over a period of 2 years and according to predefined selection criteria. Patients were selected on the basis of clinical and hormonal evidence of GH deficiency, central hypothyroidism and hypogonadotrophic hypogonadism, in the absence of an identified cause of hypopituitarism, and classified according to family history, as familial or sporadic cases.

A total of 46 cases were assessed, 17 belonged to seven apparently unrelated families with a positive history of CPHD and 29 were sporadic cases. As the majority of participating centres were adult endocrine units, only eight patients were under 18 years of age at the time of this study. All selected patients agreed to be included in the study. As there was no central registry of CPHD patients, an undetermined number of patients under the care of nonendocrine specialties may have been excluded from this study.

Clinical, hormonal and neuroradiological data were collected from each patient by physicians at each referring centre. The biochemical study was performed by measuring free T3 and T4, IGF-1, oestradiol/testosterone and PRL at baseline. As patients were studied at various centres using different commercial hormonal assays, normal values for each centre were taken into account. Anterior pituitary function was assessed by determining the response of TSH to TRH $(200 \mu \mathrm{g}$, iv), the LH and FSH responses to $\mathrm{GnRH}(100 \mu \mathrm{g}$, iv), the cortisol response to synthetic $\mathrm{ACTH}_{1-24}(250 \mu \mathrm{g}$, iv) and the GH, cortisol and ACTH responses to an insulin tolerance test $\left(0 \cdot 1 \mathrm{U} / \mathrm{kg}\right.$, iv), as described previously. ${ }^{8}$ Onset of ACTH deficiency was considered retrospectively to be the earliest age at which the stimulated cortisol levels fell below $550 \mathrm{nmol} / \mathrm{l}$. 


\section{Genomic analysis of the PROP1 gene}

Venous blood samples were obtained after informed consent using guidelines approved by the local research ethics committee and genomic DNA was extracted using standard methods. Each of the three exons of the PROP1 gene was amplified by polymerase chain reaction (PCR) using previously described flanking primer sequences. ${ }^{9}$ In brief, 100-200 ng of genomic DNA were used in $50 \mu \mathrm{l}$ reactions containing $25 \mathrm{pmol}$ of each primer, $1 \mathrm{U}$ of Taq DNA polymerase, $200 \mu \mathrm{M}$ of each dNTP, $50 \mathrm{~mm} \mathrm{KCl,} 1.5 \mathrm{~mm} \mathrm{MgCl}_{2}$, $10 \mathrm{~mm}$ Tris- $\mathrm{HCl}(\mathrm{pH} 9 \cdot 0)$. Cycle conditions consisted of initial denaturation at $95^{\circ} \mathrm{C}$ for $5 \mathrm{~min}$, followed by 35 cycles of $95^{\circ} \mathrm{C}$ for $1 \mathrm{~min}, 55^{\circ} \mathrm{C}$ for $1 \mathrm{~min}$, and $72^{\circ} \mathrm{C}$ for $1 \mathrm{~min}$, with a final extension step of $72{ }^{\circ} \mathrm{C}$ for $10 \mathrm{~min}$. The PCR products were purified using the QIAquick PCR purification kit (Qiagen) and direct sequencing of both strands of the products was carried out on a CEQ8000 capillary sequencer using the CEQ Dye Terminator Cycle Sequencing Quick Start Kit (Beckman Coulter, Fullerton, CA, USA) with the same PCR primers.

Mutations were confirmed by repeating the PCR followed by the use of appropriate restriction endonucleases for the nucleotide changes and gel electrophoresis of the digested fragments. Nomenclature for nucleotide changes followed the standard format $c$. XXX, where $\mathrm{c}$ indicates the $\mathrm{CDNA}$ sequence and XXX represents the altered nucleotide(s) of that sequence. Previously unreported nucleotide changes were screened for in a panel of 55 normal individuals (110 alleles) to assess the possibility of common polymorphisms.

\section{Results}

Germline mutations of the PROP1 gene were found in all familial cases of CPHD and in two sporadic cases (Fig. 2). A 2-bp deletion, c. 301-302delAG, was found in five families (F1, F2, F4, F6 and F9) and in both sporadic cases (F3, F8). One family (F7) had a c. $358 \mathrm{C} \rightarrow \mathrm{T}$ mutation and another (F5) had an initiation codon c. $2 \mathrm{~T} \rightarrow \mathrm{C}$ mutation. All mutations were present in homozygosity.
No other mutations of the coding sequence of the gene were present in the remaining 27 sporadic cases. Mutations were also confirmed by the use of restriction endonucleases. The $c$. 301-302delAG mutation generated a restriction site for $B c g$ I that resulted in fragments of 247, 133 and $34 \mathrm{bp}$, instead of the normal PCR product of $416 \mathrm{bp}$. The $c .358 \mathrm{C} \rightarrow \mathrm{T}$ mutation generated a Pst $\mathrm{I}$ restriction site that resulted in fragments of 448 and $131 \mathrm{bp}$, instead of the normal PCR product of $579 \mathrm{bp}$. The $c .2 \mathrm{~T} \rightarrow \mathrm{C}$ mutation eliminated a restriction site for NcoI that would normally cleave the 326-bp PCR product into fragments of 197 and 129 bp (Fig. 3).

All 19 patients with germline mutations (Table 2) had presented with growth retardation and central hypothyroidism during childhood and complete absence of puberty. GH, TSH and LH/FSH deficiencies were demonstrated in all of these patients. PRL levels were under $5 \mathrm{ng} / \mathrm{ml}$, in 15 out of 19 cases, and ACTH impairment was present in eight out of 19 cases, with an age of onset ranging from 11 to 36 years (Table 2). Magnetic resonance imaging (MRI) scans demonstrated pituitary hypoplasia or empty sella in all except one patient aged 27 years, who presented a nonenhancing sellar mass with hyperintensity in T1 and low signal in T2 (Fig. 4). This mass was initially detected during a first MRI performed at 16 years of age, and at that time measured $10 \times 10 \times 12 \mathrm{~mm}$ (height $\times$ length $\times$ width), with extension above the sellar fossa. This mass maintained these characteristics up to the age of 21 years (Fig. 4) and then underwent a reduction in volume until its current size of $5 \times 5 \times 7 \mathrm{~mm}$.

\section{Discussion}

The most frequent mutation found in this study was c. 301-302delAG, which was present in five out of seven kindreds and in the only two sporadic cases with PROP1 germline mutations. This 2-bp deletion occurs in a dinucleotide repeat mutational hotspot and is the most frequently reported mutation in patients with $\mathrm{CPHD},{ }^{9,10}$ constituting over half of all reported PROP1 defects. This deletion, which occurs in exon 2, is predicted to cause a frameshift in the coding sequence starting at codon 101 with a premature termination at
Fig. 2 Family trees of CPHD patients found to harbour PROP1 germline mutations. Individuals are represented as males (squares), females (circles), affected (filled symbols), unaffected (open symbols) and deceased (oblique line through symbol). The double line represents a consanguineous marriage. Patients F3 II-1 and F8 II-1 presented as sporadic cases (i.e. no family history of CPHD).
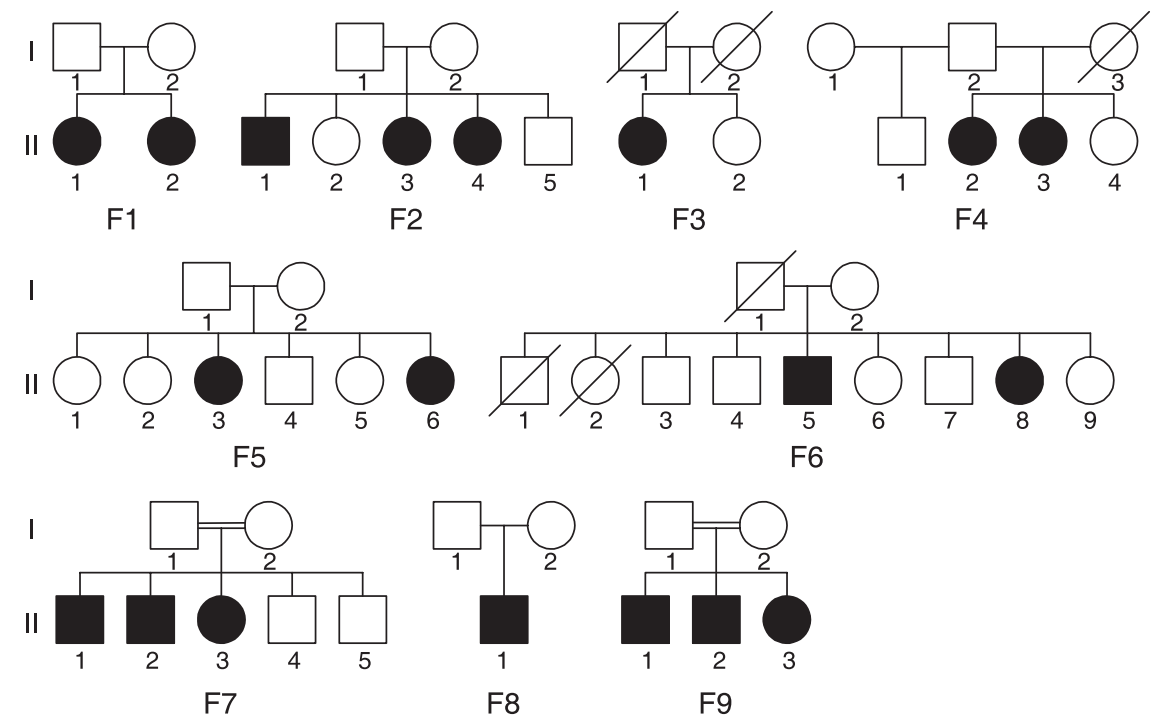
(a)

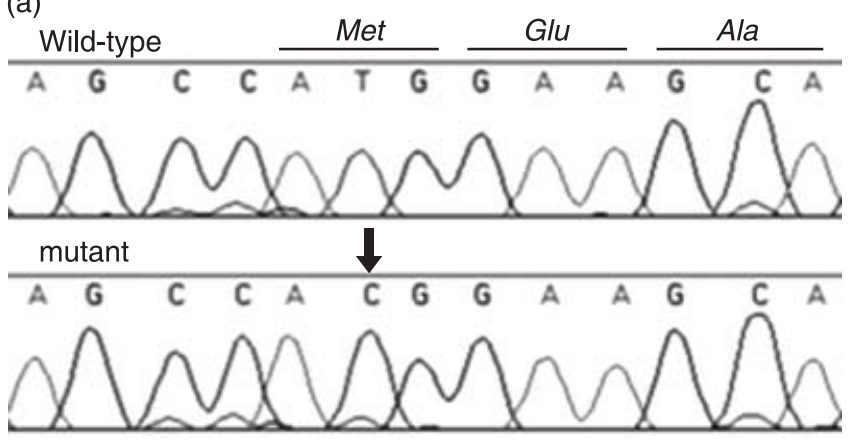

(b)

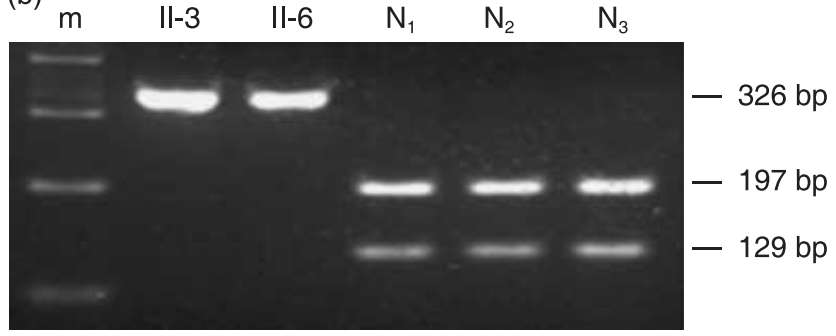

Fig. 3 Identification of a novel initiation codon mutation. (a) Partial sequencing data of the wild-type and mutant alleles in family F5 showing a $\mathrm{T}$ to $\mathrm{C}$ transition of the second base of the methionine initiation codon (arrow). This c. 2T $\rightarrow \mathrm{C}$ mutation was present in homozygosity in the affected family members. (b) Digestion of PCR amplified fragments with $\mathrm{NcoI}$ demonstrating loss of the corresponding restriction site in both patients (II-3 and II-6) from family F5. In unaffected control individuals $\left(\mathrm{N}_{1}-\mathrm{N}_{3}\right.$ shown), the presence of the $\mathrm{NcoI}$ restriction site leads to cleavage of the 326-bp PCR product into fragments of 197 and $129 \mathrm{bp}$. DNA size markers (m; 100-bp ladder) are indicated.

codon 109, leading to the loss of the DNA-binding homeodomain and the C-terminal transactivation domain of PROP1. ${ }^{4}$ Another mutation found in this study was located in exon 3 and led to a $\mathrm{C} \rightarrow \mathrm{T}$ nucleotide transition at position $c$. 358, resulting in the substitution of an arginine by a cysteine at codon 120, which has been shown to severely affect the DNA binding and transactivation ability of PROP1.

Our study revealed a novel initiation codon mutation of the PROP1 gene, which is also the first reported mutation in exon 1 of this gene. Several examples of mutations in the ATG initiation codon and in the flanking consensus sequence have been reported in association with human disease. ${ }^{11}$ Unlike some other organisms, eukaryotic ribosomes rarely initiate translation at a codon other than ATG. ${ }^{12}$ For some genes, elimination of the initiation codon can result in the use of an alternative downstream ATG codon as the translational initiation site. There are no ATG triplets upstream of the normal initiation site in the PROP1 cDNA deposited in GenBank (accession NM_006261) and there are only two that are located downstream within the coding region. The first is located at nucleotides c. 518-520 but is out of frame. The second is located at nucleotides c. 640-642 and is in frame, but lacks the flanking consensus sequence, and even if translation occurred, the resultant peptide would only have the terminal 13 residues instead of the normal 226
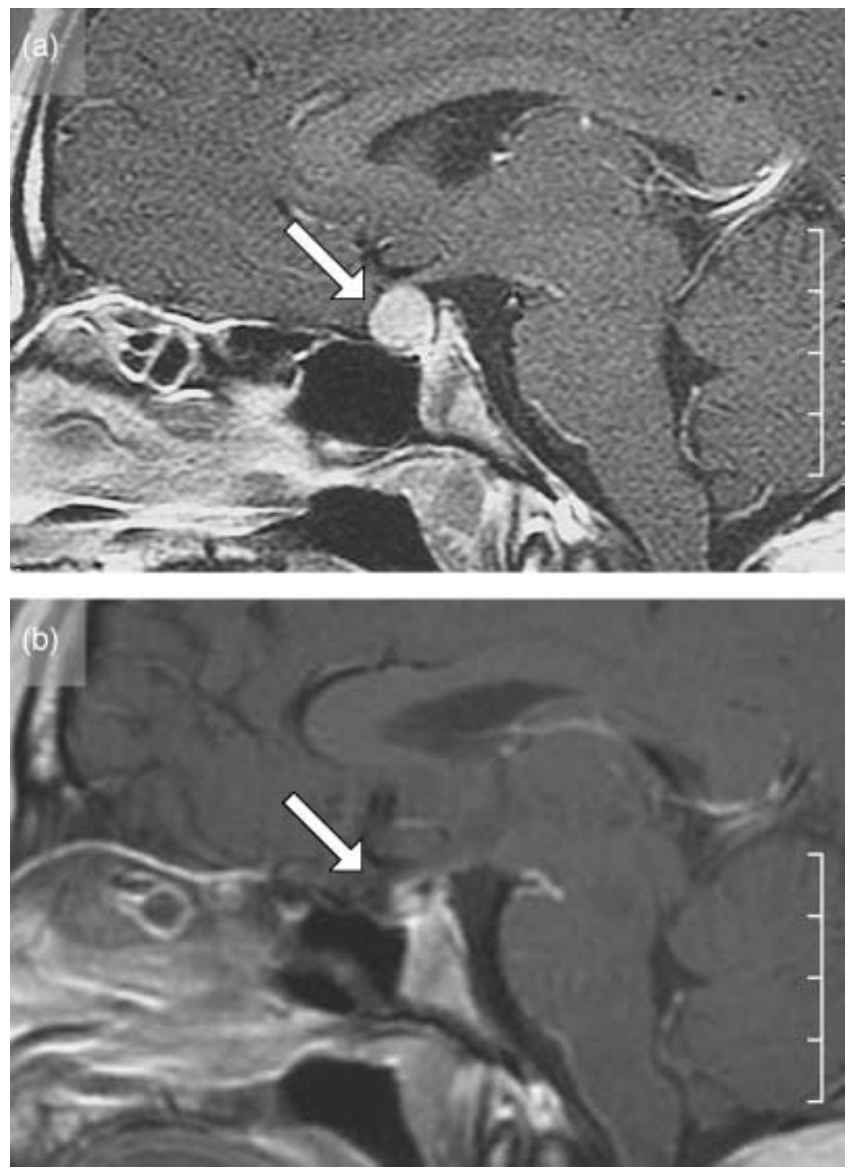

Fig. 4 MRI of the sella turcica in a woman with CPHD (patient F6 II-8, Fig. 2 and Table 2) caused by a homozygous PROP1 gene mutation (c. 301-302delAG). (a) Midsagittal T1-weighted scan at 21 years of age, showing a space occupying lesion (arrow). This lesion was nonenhancing with hyperintensity in $\mathrm{T} 1$ and low signal in $\mathrm{T} 2$ and measured $10 \times 10 \times 12 \mathrm{~mm}$ (height $\times$ length $\times$ width), with suprasellar extension. (b) Midsagittal T1-weighted scan at 27 years of age, showing regression of lesion (arrow). This lesion maintained the same signal characteristics as before, but was smaller in size, measuring $5 \times 5 \times 7 \mathrm{~mm}$. A $1 \mathrm{~cm}$ graded scale is shown on the right of the images.

amino acids that constitute the fully translated protein. The encountered mutation therefore appears to lead to a null allele that abolishes the translation of the PROP1 protein.

All patients with these mutations had deficiency of GH, TSH and LH/FSH; however, there was phenotypic variability in terms of the levels of PRL and the presence of ACTH deficiency, even among patients with the same mutation. Low levels of PRL were found in the majority of patients. Although PRL deficiency has been reported to be variable in several studies, it has not been given as much emphasis as other hormone deficiencies. This may be due to the lack of an appropriate definition of this deficiency and to the apparent lack of clinical consequences, with perhaps the exception of puerperal alactogenesis following successful fertility treatment. ${ }^{13}$ In the Ames mouse, PRL was not detectable by immunoprecipitation ${ }^{14}$ but PRL-immunoreactive cells could be identified, ${ }^{15}$ so it is conceivable that in humans some residual function may occur. ACTH impairment has been increasingly recognized as a late-onset complication in 
Table 2. Summary of patient phenotypes and mutations

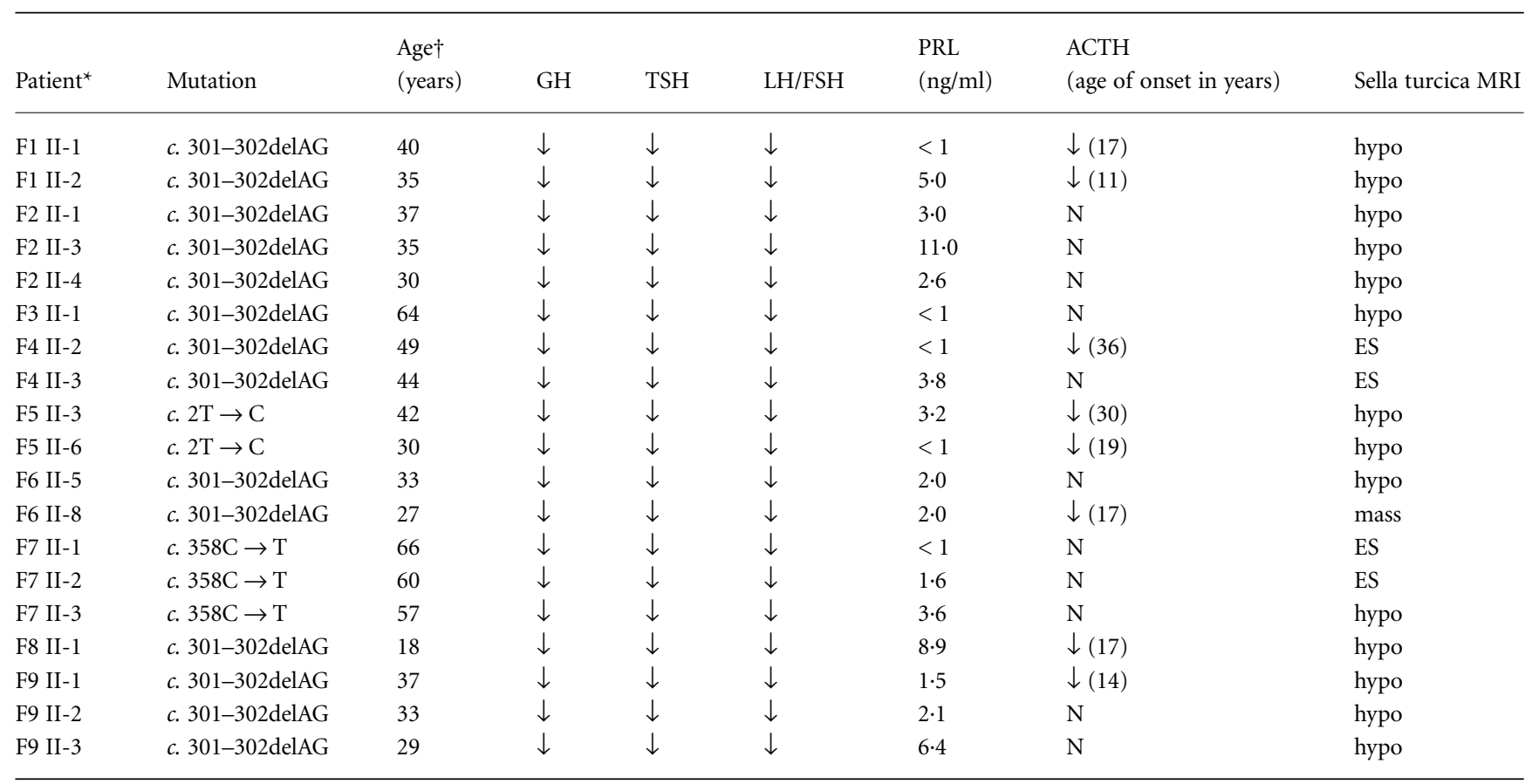

${ }^{\star}$ Identification indicates family number and position in pedigree (Fig. 2).

$\dagger$ Age at time of study.

$\mathrm{N}$, normal; $\downarrow$, deficiency; MRI, magnetic resonance imaging; hypo, pituitary hypoplasia; ES, empty sella.

patients with PROP1 mutations. A previous study of 10 patients with the $c$. 301-302delAG mutation showed that five out of six patients who were over 40 years of age developed ACTH deficiency compared to only one out of four patients below the age of $40 .{ }^{16}$ Several of our oldest patients (up to the age of 66 years) have not developed this deficiency whereas others presented abnormal cortisol responses as early as 11 years of age. The cause of ACTH deficiency, which does not occur in the Ames mouse model, is currently unknown but may indicate a possible role of PROP1 in the differentiation and/or maintenance of corticotroph cells. In agreement with previous reports, ${ }^{17}$ none of our patients with the mutation $c .358 \mathrm{C} \rightarrow \mathrm{T}$ presented this deficiency and this may be related to some degree of residual activity conferred by this missense mutation. ${ }^{4}$

Pituitary size was also variable among patients. MRI demonstrated pituitary hypoplasia or empty sellae in all patients except one, who presented an enlarged sellar mass. Pituitary enlargement has been frequently observed in young patients with PROP1 mutations, but this feature appears to be followed by degeneration and regression of the mass, often resulting in an empty sella with a small remainder of pituitary tissue. ${ }^{6,7}$ These pituitary masses, with one exception, ${ }^{18}$ have only been reported in young children and this contrasts with the MRI results that one of our patients maintained up to the age of 21 years. In the remaining patients, because of the lack of adequate imaging studies in childhood, it was not possible to confirm the previous existence of any pituitary mass, although this would be compatible with the high frequency of empty sella currently observed in this group of patients.

Genotype-phenotype correlations were not established because of the limited number of patients in each mutation group. However, the phenotype associated with the novel initiation codon mutation does not appear to differ from that conferred by the more frequent 2-bp deletion.

Only a small proportion (6.9\%) of sporadic cases was found to harbour PROP1 mutations. The majority of cases are thus likely to be phenocopies resulting from unrecognized acquired causes. Other genes responsible for CPHD, such as PIT1 and HESX1, were not analysed in this study as they are normally associated with a different phenotype, but mutations of other transcription factors such as $L H X 3$ or $L H X 4$ or other unknown genetic defects cannot be excluded in these patients. ${ }^{19}$

Given the mode of inheritance of autosomal recessive disorders, most patients with mutations would not be expected to present any family history of the disorder, as each sibling has only a $25 \%$ probability of being affected. In this study, the relatively low ratio of mutated sporadic to familial cases suggests a possible selection bias for familial cases at the referring centres, although this would not alter the main conclusions of the study.

Testing for PROP1 mutations in CPHD patients, even in sporadic cases, may be warranted in view of the implications in their clinical management, such as early awareness of the failure to enter spontaneous puberty, of the risk of future ACTH deficiency and of the natural history of any existing sellar mass.

In conclusion, in this study of a cohort of CPHD patients due to PROP1 mutations, we observed variable expression of PRL and ACTH levels and an unusual case of persistence of a sellar mass into adulthood. Furthermore, we identified the first mutation in the initiation codon of the PROP1 gene and this further expands the spectrum of known mutations responsible for hypopituitarism. 


\section{Acknowledgements}

We thank the following physicians for their contribution with patient samples and clinical data: Alice Mirante (Coimbra), Beatriz Serra (Oporto), Clotilde Limbert (Lisbon), Fátima Borges (Oporto), Helena Cardoso (Oporto), Luís Simões Moura (Coimbra), Olinda Marques (Braga) and Paula Mendes (Oporto).

\section{References}

1 Duquesnoy, P., Roy, A., Dastot, F., Ghali, I., Teinturier, C., Netchine, I., Cacheux, V., Hafez, M., Salah, N., Chaussain, J.L., Goossens, M., Bougneres, P. \& Amselem, S. (1998) Human Prop-1: cloning, mapping, genomic structure. Mutations in familial combined pituitary hormone deficiency. FEBS Letters, 437, 216-220.

2 Savage, J.J., Yaden, B.C., Kiratipranon, P. \& Rhodes, S.J. (2003) Transcriptional control during mammalian anterior pituitary development. Gene, 319, 1-19.

3 Sornson, M.W., Wu, W., Dasen, J.S., Flynn, S.E., Norman, D.J., O’Connell, S.M., Gukovsky, I., Carriere, C., Ryan, A.K., Miller, A.P., Zuo, L., Gleiberman, A.S., Andersen, B., Beamer, W.G. \& Rosenfeld, M.G. (1996) Pituitary lineage determination by the Prophet of Pit-1 homeodomain factor defective in Ames dwarfism. Nature, 384, 327-333.

4 Wu, W., Cogan, J.D., Pfaffle, R.W., Dasen, J.S., Frisch, H., O'Connell, S.M., Flynn, S.E., Brown, M.R., Mullis, P.E., Parks, J.S., Phillips, J.A. 3rd \& Rosenfeld, M.G. (1998) Mutations in PROP1 cause familial combined pituitary hormone deficiency. Nature Genetics, 18, 147149.

5 Mody, S., Brown, M.R. \& Parks, J.S. (2002) The spectrum of hypopituitarism caused by PROP1 mutations. Best Practice and Research. Clinical Endocrinology and Metabolism, 16, 421-431.

6 Voutetakis, A., Argyropoulou, M., Sertedaki, A., Livadas, S., Xekouki, P., Maniati-Christidi, M., Bossis, I., Thalassinos, N., Patronas, N. \& Dacou-Voutetakis, C. (2004) Pituitary magnetic resonance imaging in 15 patients with Prop1 gene mutations: pituitary enlargement may originate from the intermediate lobe. Journal of Clinical Endocrinology and Metabolism, 89, 2200-2206.

7 Teinturier, C., Vallette, S., Adamsbaum, C., Bendaoud, M., Brue, T. \& Bougneres, P.F. (2002) Pseudotumor of the pituitary due to PROP-1 deletion. Journal of Pediatric Endocrinology and Metabolism, 15, 95-101.

8 Trainer, P. \& Besser, M. (1995) The Bart's Endocrine Protocols. Churchill Livingstone, Edinburgh.

9 Deladoey, J., Fluck, C., Buyukgebiz, A., Kuhlmann, B.V., Eble, A., Hindmarsh, P.C., Wu, W. \& Mullis, P.E. (1999) 'Hot spot' in the $P R O P 1$ gene responsible for combined pituitary hormone deficiency. Journal of Clinical Endocrinology and Metabolism, 84, 1645-1650.

10 Cogan, J.D., Wu, W., Phillips, J.A. 3rd, Arnhold, I.J., Agapito, A., Fofanova, O.V., Osorio, M.G., Bircan, I., Moreno, A. \& Mendonca, B.B. (1998) The PROP1 2-base pair deletion is a common cause of combined pituitary hormone deficiency. Journal of Clinical Endocrinology and Metabolism, 83, 3346-3349.

11 Kozak, M. (2002) Emerging links between initiation of translation and human diseases. Mammalian Genome, 13, 401-410.

12 Kozak, M. (1996) Interpreting cDNA sequences: some insights from studies on translation. Mammalian Genome, 7, 563-574.

13 Voutetakis, A., Sertedaki, A., Livadas, S., Maniati-Christidi, M., Mademtzis, I., Bossis, I., Dacou-Voutetakis, C. \& Messinis, I.E. (2004) Ovulation induction and successful pregnancy outcome in two patients with Prop1 gene mutations. Fertility and Sterility, 82, $454-457$
14 Slabaugh, M.B., Lieberman, M.E., Rutledge, J.J. \& Gorski, J. (1981) Growth hormone and prolactin synthesis in normal and homozygous Snell and Ames dwarf mice. Endocrinology, 109, 1040-1046.

15 Gage, P.J., Roller, M.L., Saunders, T.L., Scarlett, L.M. \& Camper, S.A. (1996) Anterior pituitary cells defective in the cell-autonomous factor, df, undergo cell lineage specification but not expansion. Development, 122, 151-160.

16 Pernasetti, F., Toledo, S.P., Vasilyev, V.V., Hayashida, C.Y., Cogan, J.D., Ferrari, C., Lourenco, D.M. \& Mellon, P.L. (2000) Impaired adrenocorticotropin-adrenal axis in combined pituitary hormone deficiency caused by a two-base pair deletion (301-302delAG) in the prophet of Pit-1 gene. Journal of Clinical Endocrinology and Metabolism, 85, 390-397.

17 Fluck, C., Deladoey, J., Rutishauser, K., Eble, A., Marti, U., Wu, W. \& Mullis, P.E. (1998) Phenotypic variability in familial combined pituitary hormone deficiency caused by a PROP1 gene mutation resulting in the substitution of Arg $\rightarrow$ Cys at codon 120 (R120C). Journal of Clinical Endocrinology and Metabolism, 83, 3727-3734.

18 Crone, J., Pfaffle, R., Stobbe, H., Prayer, D., Gomez, I. \& Frisch, H. (2002) Familial combined pituitary hormone deficiency caused by PROP-1 gene mutation. Growth patterns and MRI studies in untreated subjects. Hormone Research, 57, 120-126.

19 Dattani, M.T. (2005) Growth hormone deficiency and combined pituitary hormone deficiency: does the genotype matter? Clinical Endocrinology, 63, 121-130.

20 Bottner, A., Keller, E., Kratzsch, J., Stobbe, H., Weigel, J.F., Keller, A., Hirsch, W., Kiess, W., Blum, W.F. \& Pfaffle, R.W. (2004) PROP1 mutations cause progressive deterioration of anterior pituitary function including adrenal insufficiency: a longitudinal analysis. Journal of Clinical Endocrinology and Metabolism, 89, 5256-5265.

21 Agarwal, G., Bhatia, V., Cook, S. \& Thomas, P.Q. (2000) Adrenocorticotropin deficiency in combined pituitary hormone deficiency patients homozygous for a novel PROP1 deletion. Journal of Clinical Endocrinology and Metabolism, 85, 4556-4561.

22 Fofanova, O., Takamura, N., Kinoshita, E., Parks, J.S., Brown, M.R., Peterkova, V.A., Evgrafov, O.V., Goncharov, N.P., Bulatov, A.A., Dedov, I.I. \& Yamashita, S. (1998) Compound heterozygous deletion of the PROP-1 gene in children with combined pituitary hormone deficiency. Journal of Clinical Endocrinology and Metabolism, 83, 2601-2604.

23 Riepe, F.G., Partsch, C.J., Blankenstein, O., Monig, H., Pfaffle, R.W. \& Sippell, W.G. (2001) Longitudinal imaging reveals pituitary enlargement preceding hypoplasia in two brothers with combined pituitary hormone deficiency attributable to PROP1 mutation. Journal of Clinical Endocrinology and Metabolism, 86, 4353-4357.

24 Tatsumi, K.I., Kikuchi, K., Tsumura, K. \& Amino, N. (2004) A novel PROP1 gene mutation (157delA) in Japanese siblings with combined anterior pituitary hormone deficiency. Clinical Endocrinology, 61, 635-640.

25 Paracchini, R., Giordano, M., Corrias, A., Mellone, S., Matarazzo, P., Bellone, J., Momigliano-Richiardi, P. \& Bona, G. (2003) Two new PROP1 gene mutations responsible for compound pituitary hormone deficiency. Clinical Genetics, 64, 142-147.

26 Vallette-Kasic, S., Barlier, A., Teinturier, C., Diaz, A., Manavela, M., Berthezene, F., Bouchard, P., Chaussain, J.L., Brauner, R., PellegriniBouiller, I., Jaquet, P., Enjalbert, A. \& Brue, T. (2001) PROP1 gene screening in patients with multiple pituitary hormone deficiency reveals two sites of hypermutability and a high incidence of corticotroph deficiency. Journal of Clinical Endocrinology and Metabolism, 86, 4529-4535.

27 Voutetakis, A., Maniati-Christidi, M., Kanaka-Gantenbein, C., 
Dracopoulou, M., Argyropoulou, M., Livadas, S., Dacou-Voutetakis, C. \& Sertedaki, A. (2004) Prolonged jaundice and hypothyroidism as the presenting symptoms in a neonate with a novel Prop1 gene mutation (Q83X). European Journal of Endocrinology, 150, 257-264.

28 Osorio, M.G., Kopp, P., Marui, S., Latronico, A.C., Mendonca, B.B. \& Arnhold, I.J. (2000) Combined pituitary hormone deficiency caused by a novel mutation of a highly conserved residue (F88S) in the homeodomain of PROP-1. Journal of Clinical Endocrinology and Metabolism, 85, 2779-2785.

29 Vieira, T.C., Dias da Silva, M.R., Cerutti, J.M., Brunner, E., Borges, M.,
Arnaldi, L.T., Kopp, P. \& Abucham, J. (2003) Familial combined pituitary hormone deficiency due to a novel mutation R99Q in the hot spot region of Prophet of Pit-1 presenting as constitutional growth delay. Journal of Clinical Endocrinology and Metabolism, 88, $38-44$.

30 Reynaud, R., Barlier, A., Vallette-Kasic, S., Saveanu, A., Guillet, M.P., Simonin, G., Enjalbert, A., Valensi, P. \& Brue, T. (2005) An uncommon phenotype with familial central hypogonadism caused by a novel PROP1 gene mutant truncated in the transactivation domain. Journal of Clinical Endocrinology and Metabolism, 90, 4880-4887. 